Betristasia Puspitasari, S.ST.M.Kes : Hubungan Pengetahuan Ibu Bayi 0-12 Bulan Tentang Posyandu Dengan Minat Melakukan Imunisasi Dasar Ke Posyandu

\title{
HUBUNGAN PENGETAHUAN IBU BAYI 0 - 12 BULAN TENTANG POSYANDU DENGAN MINAT MELAKUKAN IMUNISASI DASAR KE POSYANDU (Di Posyandu Kamboja Desa Sugihwaras Kecamatan Saradan Kabupaten Madiun)
}

Betristasia Puspitasari, S.ST.M.Kes 1, Vika Putri Anggraeni 2

Akademi Kebidanan Dharma Husada Kediri Jawa Timur

\begin{abstract}
ABSTRAK
Posyandu sendiri merupakan bentuk Upaya Kesehatan Bersumber Daya Masyarakat (UKBM) yang dibentuk atas dasar kebutuhan masyarakat, dikelola oleh masyarakat dan untuk masyarakat, dengan bimbingan dari petugas puskesmas dan lintas sektor terkait pelayanan kesehatan dasar, pelayanan kesehatan yang mempercepat penurunan AKI dan AKB yang sekurang - kurangnya mencakup 5 kegiatan yakni, KIA, KB, Imunisasi, Gizi, dan Penanggulangan diare. Di Posyandu inilah balita akan mendapatkan Layanan Imunisasi. Tujuan penelitian ini adalah mengetahui Hubungan pengetahuan ibu bayi usia $0-12$ bulan tentang posyandu dengan minat melakukan imunisasi dasar ke posyandu di Posyandu Kamboja desa Sugihwaras Kecamatan Saradan Kabupaten Madiun.

Penelitian dilaksanakan tanggal 12 Mei 2015. Desain penelitian analitik dengan pendekatan cross sectional. Variabel independen adalah pengetahuan ibu bayi usia $0-12$ bulan tentang posyandu. Variabel dependen adalah minat ibu bayi usia 0- 12 bulan melakukan imunisasi dasar ke posyandu. Populasi penelitian semua ibu bayi usia $0-12$ bulan yang datang di Posyandu Kamboja Desa Sugihwaras Kecamatan Saradan Kabupaten Madiun. Teknik sampling menggunakan accidental sampling diperoleh populasi sebanyak 50 responden dari 35 responden. Instrumen penelitian menggunakan kuisoner. Data dianalisis menggunakan Sperman Rank.

Hasil Penelitian dipeoleh bahwa 17 (48,57\%) responden memiliki pengetahuan kurang tentang posyandu dan $16(45,71 \%)$ responden memiliki minat rendah untuk melakukan imunisasi dasar ke posyandu. Hasil uji statistik adalah $\mathrm{Z}$ hitung $=1$ dengan $\alpha=0,05$. Oleh karena itu $\mathrm{Z}$ hitung lebih besar dari $\mathrm{Z}$ tabel $(1>0,0596)$ maka dapat disimpulkan Ho ditolak dan H1 diterima artinya ada hubungan antara pengetahuan ibu bayi usia 0 - 12 bulan tentang posyandu dengan minat melakukan imunisasi dasar ke posyandu di Posyandu Kamboja Desa Sugihwaras Kecamatan Saradan Kabupaten Madiun.

Pengetahuan berhubungan sekali dalam menentukan minat ibu bayi. Pengetahuan ibu bayi usia 0 -12 bulan yang baik tentang posyandu akan menjadi dasar ibu bayi untuk minat melakukan imunisasi dasar ke posyandu . kerjasama tenaga kesehatan dengan ibu bayi usia $0-12$ bulan sangatlah penting dalam peningkatan pengetahuan dan minat ibu untuk datang imunisasi ke posyandu.
\end{abstract}

\section{Kata Kunci : Pengetahuan, Ibu bayi, Posyandu, Minat, Imunisasi}




\section{PENDAHULUAN}

Kesehatan merupakan hak azasi (UUD 1945 , pasal $28 \mathrm{H}$ ayat 1 dan UU No.36 Tahun 2009 tentang Kesehatan) dan sekaligus investasi, sehingga perlu diupayakan, diperjuangkan dan ditingkatkan oleh setiap individu dan oleh seluruh komponen bangsa, agar masyarakat dapat menikmati hidup sehat, dan pada ahkirnya dapat mewujudkan daerah kesehatan masyarakat yang optimal. Salah satu bentuk upaya pemberdayaan masyarakat di bidang kesehatan adalah menumbuhkembangkan Posyandu (Kemenkes RI, 2011:1-2).

Posyandu merupakan unit pelayanan kesehatan di lapangan, yang diselenggarakan oleh masyarakat untuk masyarakat dengan dukungan teknis Puskesmas, Departemen Agama, Departemen Pertanian, dan BKKBN (Purwandari,2011:49).

Imunisasi sendiri merupakan pencegahan primer terhadap penyakit infeksi yang paling efektif dan murah.Walaupun demikian, berdasarkan hasil Riskesdas 2010. Di Indonesia, cakupan imunisasi BCG sudah mencapai 93\%, tetapi cakupan imunisasi dasar lain masih di bawah 90\%, sedangkan di beberapa kawasan negara Asean seperti Brunei Darussalam, Singapura, Malaysia, dan Vietnam, cakupan imunisasi dasarnya sudah mencapai lebih dari 90\%.Cakupan imunisasi dasar yang rendah beberapa propinsi di Indonesia, antara lain disebabkan alokasi anggaran kesehatan yang rendah untuk pencegahan baik di propinsi maupun di kabupaten akibat sistem desentralisasi,Rasio jumlah desa dengan Posyandu yang rendah yaitu rerata nasional 3,55 (1 desa mempunyai 3-4 Posyandu) imunisasi dasar lengkap minimal 80\%. Tahun 2010 rerata nasional desa UCI adalah 75,31\%, sedangkan target pemerintah adalah 100 persen desa mencapai UCI pada tahun 2014 (Sari Pediatri, 2013:284).

Disisi lain terlihat hal yang kurang baik seperti cakupan imunisasi dasar lengkapnyasangat rendah yaitu $46,2 \%$ padahal kita harus mengejar target SPM 100\% di tahun 2015 (Endang, 2015).

Untuk Jawa Timur cakupan imunisasi lengkap adalah 46,7\% sedikit lebih besar
Posyandu dilaksanakan sebulan sekali, yang ditentukan oleh LKMD, Kader, tim perggerak PKK desa kelurahan, dan petugas KB. Sasaran Posyandu adalah Bayi/balita, ibu hamil/ibu menyusui, wanita usia subur (WUS), pasangan usia subur (PUS) (Purwandari,2011:52).

Posyandu sendiri merupakan bentuk Upaya Kesehatan Bersumber Daya Masyarakat (UKBM)yang dibentuk atas dasar kebutuhan masyarakat, dikelola oleh masyarakat dan untuk masyarakat, dengan bimbingan dari petugas puskesmas dan lintas sektor terkait pelayanan kesehatan dasar, pelayanan kesehatan yang mempercepat penurunan AKI dan AKB yang sekurang - kurangnya mencakup 5 kegiatan yakni, KIA, KB, Imunisasi, Gizi, dan Penanggulangan diare. Di Posyandu inilah balita akan mendapatkan Layanan Imunisasi (Rika, 2014:1).

Di Indonesia sebagai gambaran tingkat kesehatan di masyarakat masih memerlukan perhatian khusus yaitu : angka kematian kasar (CMR) : 7,51 per 1000/tahun, angka kematian bayi (IMR) : 48 per 1000 lahir hidup/tahun, angka kematian balita (U5MR) : 56 per 1000 lahir hidup/tahun, angka kematian ibu hamil (MMR) : 470 per 100.000 lahir hidup/tahun, cakupan imunisasi: BCG 85\%, DPT 64\%, Polio $74 \%$, HB1 91\%, HB2 84,4\%, HB3 83,0\%, TT ibu hamil : TT1 84\%, dan TT2 775\% (WHO) (Ranuh,2008: 2).

Bayi - bayi di Indonesia yang di imunisasikan setiap tahun sekitar $90 \%$ dari sekitar 4,5 juta bayi lahir. Hal itu karena masih ada habatan geografis, jarak, jangkauan layanan, transportasi, ekonomi dll, artinya setiap tahun ada $10 \%$ bayi (sekitar 450.000 bayi) yang belum mendapatkan imunisasi, sehingga dalam 5 tahun menjadi 2 juta anak yang belum mendapat imunisasi dasar lengkap (Soedjatmiko, 2015)

dibanding angka Nasional 46,2\%. Wilayah dengan masalah cakupan imunisasi lengkap antara 8,5 - 22,9\% (Endang, $2015: 37$ ).

Kepala Dinas Kesehatan Kota Madiun, Agung Sulistya Wardani, mengatakan, pada 2010 ditemukan satu kasus defteri. Pada 2011 
temuan kasusnya meningkat menjadi tiga kasus. Sedangkan pada 2012, sejak Januari hingga September, sudah ditemukan 18 kasus difteri(Supratiwi, 2012:1).

Dalam hal ini Pengetahuan yang dimiliki oleh ibu balita bahwa sebagian besar mereka belum mengetahui manfaat secara menyeluruh tentang fungsi dari posyandu selama ini, ibu hanya melakukan imunisasi saja setelah anak mereka berumur 1 tahun lebih, maka kegiatan kunjungan ke posyandu berangsur - angsur mengalami penurunan dan tidak rutin lagi. Sehingga minat ibu untuk mengimunisasikan bayinya menurun, ini disebabkan oleh beberapa faktor antara lain : pendidikan, dukungan keluarga, jarak tempat tinggal (Leni, 2012:11).

Penyebab utama rendahnya pencapaian UCI (Universal Cild Immunization) di Indonesia adalah karena rendahnya akses pelayanan dan tingginya angka drop out. Hal ini terjadi karena akses tempat pelayanan yang sulit dijangkau, jadwal pelayanan yang tidak teratur dan tidak sesuai dengan kegiatan masyarakat, kurangnya tenaga pelaksana, tidak tersedianya buku KIA (Kesehatan Ibu dan Anak) atau kartu imunisasi, rendahnya kesadaran dan pengetahuan masyarakat tentang manfaat, waktu pemberian imunisasi, serta gejala ikutan imunisasi. Faktor budaya dan pendidikan serta kondisi sosial ekonomi juga ikut mempengaruhi rendahnya capaian UCI desa/kelurahan (Kemenkes, 2010).

Dampak apabila anak tidak diimunisasikan, maka tubuhnya tidak mempunyai kekebalan yang spesifik terhadap penyakit tersebut. Bila kuman berbahaya yang masuk cukup banyak maka tubuh tidak mampu melawan kuman tersebut sehingga bisa menyebabkan sakit berat, cacat atau meninggal. Anak yang tidak diimunisasikan akan menyebarkan kuman kuman disekitarnya sehingga dapat menimbulkan wabah yang menyebar kemana mana menyebabkan cacat atau kematian lebih banyak (Soedjatmiko, 2015)

Berbagai upaya telah dilakukan untukmeningkatkan cakupan imunisasi, seperti yang dilakukan di beberapa negara Eropa dengan memberikan reword dan punishment pada warga maupun tenaga kesehatan yang terampil dalam mendorong meningkatkan cakupan imunisasi (Moran, 2007).
Sekitar 44\% dari alasan terkait tidak selesainya seluruh jadwal imunisasi (under vaccination) berhubungan dengan sistem imunisasi , 28\% terkait minat dan pengetahuan orang tua. Sekitar $32 \%$ dari alasan yang terkait dengan tidak memberikan imunisasi kepada bayinya (non vaccination) berhubungan dengan sistem imunisasi, sedangkan $42 \%$ terkait dengan minat dan pengetahunan orang tua (Rainey, 2007).

\section{METODE}

Desain yang digunakan adalah pada penelitian ini adalah penelitian analitik korelasional dengan pendekatan Croos Sectional. Metode penelitian ini dilakukan secara cross-sectional yaitu jenis penelitian yang menekankan waktu pengukuran atau observasi data variable independen dan dependen hanya satu kali pada satu saat. (Nursalam, 2008: 83).

Variabel dalam penelitian ini variable independen adalah pengetahuan ibu bayi $0-12$ bulan tentang posyandu dan variabel dependen adalah minat ibu bayi $0-12$ melakukan imunisasi dasar ke posyandu.

Populasi dalam penelitian ini adalah semua ibu yang memiliki bayi di Posyandu Kamboja, Desa Sugihwaras, Kecamatan Saradan, Kabupaten Madiun sebanyak 50 responden.

Dalam penelitian ini menggunakan teknik Accidental Sampling. Jenis instrumen yang digunakan dalam penelitian ini adalah kuesioner. Kuesioner merupakan teknik pengumpulan data yang dilakukan dengan cara memberi seperangkat pertanyaan atau pernyataan tertulis kepada responden untuk dijawabnya. Analisis yang digunakan Spearman Rank. 


\section{HASIL}

a. Tabel I: Tabel Silang Hubungan Pengetahuan Ibu Bayi Usia 0 - 12 Bulan Tentang Posyandu Dengan Minat Melakukan Imunisasi Dasar Ke Posyandu

\begin{tabular}{|c|c|c|c|c|c|c|c|c|}
\hline Minat & & iggi & & & & dah & & lah \\
\hline Pengetahuan & $\mathrm{N}$ & $\%$ & $\mathrm{~N}$ & $\%$ & $\mathrm{~N}$ & $\%$ & $\mathrm{~N}$ & $\%$ \\
\hline Baik & 4 & 45,7 & 0 & 0 & 6 & 17,1 & 10 & 28,5 \\
\hline Cukup & 2 & 5,7 & 1 & 2,8 & 4 & 45,7 & 7 & 20 \\
\hline Kurang & 8 & 22,8 & 3 & 8,57 & 5 & 71,4 & 16 & 45,7 \\
\hline Jumlah & 14 & 40 & 4 & 45,7 & 15 & 42,8 & 33 & 94,2 \\
\hline Spearman Rank(Rho) & $\mathrm{Z}_{\mathrm{Hi}}$ & $\mathrm{g}=0, \mathrm{~S}$ & & & $\mathrm{Z}_{\mathrm{ta}}$ & $=0$ & 596 & \\
\hline
\end{tabular}

\section{DISKUSI}

Hasil analisa menggunakan Spermen Rank diketahui bahwa $Z_{\text {hitung }}$ sebesar 1 dengan $\alpha=$ 0,05 dan $Z_{\text {tabel }} 0,0596$ sehingga $Z_{\text {hitung }}>Z_{\text {tabel }}(1$ $>0,0596)$ Maka dapat disimpulkan bahwa $\mathrm{H}_{0}$ ditolak dan $\mathrm{H}_{1}$ diterima, artinya ada hubungan pengetahuan ibu bayi usia $0-12$ bulan tentang posyandu dengan minat melakukan imunisasi dasar ke posyandu.

Menurut Notoadmojo (2010) pengetahuan adalah hasil tahu dari manusia, yang sekedar menjawab pertanyaan "what" misalnya apa air, apa manusia, apa alam dan sebagainya.

Dari data diatas menunjukkan bahwa adanya korelasi antara pengetahuan ibu bayi usia $0-12$ bulan dengan minat melakukan imunisasi dasar ke posyandu. Semakin tinggi pengetahuan responden tentang posyandu maka semakin tinggi minat ibu untuk melakukan imunisasi dasar ke posyandu. Pengetahuan menjadi faktor yang sangat penting untuk terbentuknya tindakan seseorang termasuk kemandirian serta keinginan dalam melakukan imunisasi dasar.

Seseorang yang mempunyai pengetahuan yang baik akan cenderung berusaha mencari kebenaran atas pengetahuan yang dimilikinya. Ketika seseorang sudah benar - benar mengetahui segala sesuatu tentang posyandu, dan merasa yakin dengan pengetahuan yang diperoleh maka mereka akan bersikap positif dan memiliki minat yang tinggi untuk melakukan atau menerapkannya. Sehingga minat yang dulunya tidak dimiliki karena kurangnya pengetahuan, setelah mendapatkan pengetahuan yang benar, minat responden akan berkembang dari yang dulunya tidak berminat untuk melakukan imunisasi sekarang menjadi minat untuk datang ke posyandu untuk melakukan imunisasi.

Namun, dari hasil penelitian masih ada responden yang mempunyai pengetahuan kurang dengan minat rendah. Pengetahuan yang kurang menyebabkan responden tidak memiliki perhatian terhadap imunisasi, sehingga tidak timbul rasa motivasi untuk mengetahui lebih dalam tentang imunisasi dasar, maka responden kurang berminat untuk melakukan imunisasi dasar ke posyandu. Sehingga, selain dari perasaan senang dan perhatian, untuk mengetahui berminat atau tidaknya seseorang terhadap suatu objek dapat dilihat dari pengetahuan yang dimilikinya.

Dari uraian diatas menyimpulkan bahwa responden yang kurang mengetahui tentang posyandu cenderung tidak berminat untuk melakukan imunisasi dasar ke posyandu. Sehingga, jadwal imunisasi tidak teratur yang 
menyebabkan kekebalan tubuh bayi berkurang. Apabila bayi tidak melakukan imunisasi secara lengkap maka penyakit mudah terserang penyakit dan mudah tertular orang yang sakit.

Berdasarkan hasil penelitian juga terdapat responden yang memiliki pengetahuan baik dengan minat tinggi. Namun, dalam kenyataan, adanya minat yang tinggi belum digunakan oleh responden.

Minat merupakan sumber motivasi yang mendorong orang melakukan apa saja yang mereka inginkan bila mereka bebas memilih (Kartini, 1990 : 102).

Hal ini terbukti masih banyak responden yang belum tahu tentang posyandu dan berminat melakukan imunisasi ke posyandu, padahal mereka memiliki minat yang tinggi untuk melakukannya. Penyebabnya adalah kurangnyakeyakinan responden karena pengetahuan yang dimiliki tentang posyandu belum tentu benar, selain itu juga karena tidak adanya dukungan atau motivasi dari suami maupun anggota keluarga yang lain. Sehingga meskipun responden memiliki pengetahuan yang cukup baik tentang posyandu, mereka tidak begitu tertarik melakukan imunisasi dasar.

Minat seseorang sebenarnya bukan hanya dari keinginan sendiri tetapi juga dari orang lain. Diharapkan dengan adanya motivasi dari orang lain terutama suami atau keluarga dapat menumbuhkan minat responden dan juga dapat menjadi pendorong bagi responden untuk lebih aktif dalam menambah pengetahuan yang benar dan tepat tentang Posyandu.

Berbagai informasi yang baik media cetak maupun media elektronik dapat dijadikan sebagai sumber untuk menambah pengetahuan tentang posyandu sehingga minat untuk melakukan imunisasi dasar pada bayi usia $0-12$ bulan akan semakin tinggi.

Menumbuhkan minat seseorang untuk melakukan imunisasi dasar pada bayinya merupakan suatu tantangan bagi tenaga kesehatan, sehingga petugas kesehatan yang dianggap tahu diharapkan dapat terus memberikan motivasi dan dapat menjadikan fasilitas sebagai sumber informasi tentang posyandu dan imunisasi sehingga ibu dapat lebih yakin setelah menerima informasi dari tenaga kesehatan. Karena tenaga kesehatan dalam hal ini sangatlah berperan penting dalam kesehatan masyarakat, sehingga pengetahuan yang benar sangat berpengaruh untuk menimbulkan minat para ibu bayi usia $0-12$ bulan.

\section{SIMPULAN}

Berdasarkan hasil penilitian yang telah dilakukan pada tanggal 12 Mei 2015 di Posyandu Kamboja di Desa Sugihwaras Kecamatan Saradan Kabupaten Madiun dengan jumlah responden 35 dapat disimpulkan sebagai berikut :

1. Pengetahuan ibu bayi usia $0-12$ bulan tentang posyandu menunjukkan Pengetahuan Ibu Kurang 17 responden $(48,57 \%)$

2. Minat ibu bayi usia $0-12$ bulan Imunisasi Dasar ke Posyandu menunjukkan minat ibu rendah 16 responden $(45,71 \%)$

3. Berdasarkan hasil perhitungan dengan menggunakkan uji statistik Sperman Rank diketahui bahwa $Z_{\text {hitung }}$ sebesar 1 dengan $\alpha$ $=0,05$ dan $Z_{\text {tabel }} 0,0596$ sehingga $Z$ hitung $>\mathrm{Z}$ tabel $(1>0,0596)$ Maka dapat disimpulkan bahwa $\mathrm{H}_{0}$ ditolak dan $\mathrm{H}_{1}$ diterima, artinya ada hubungan pengetahuan ibu bayi usia $0-12$ bulan tentang posyandu dengan minat melakukan imunisasi dasar ke posyandu. 


\section{DAFTAR PUSTAKA}

Ahmadi, Abu. 2009. Psikologi Umum. Jakarta : PT. Rineka Cipta.

Antarnews, 2012. Temuan Kasus Difteri di Kota Madiun. [Online] (Update 2012) Diakses dari http://m.antaranews.com/berita/341374/ temuan-kasus-difteri-di-kota-madiunmeningkat. [12 Maret 2015].

Dinas Kesehatan Propinsi Jawa Timur. 2005. Buku Pegangan Kader Posyandu.

Ewintri, 2013. Faktor-faktor yang Mempengaruhi Pemberian Imunisasi. [Online] (Update 2013). Diakses dari : http://ewintribengkulu.blogspot.com/201 3/05/faktor-faktor-yangmempengaruhi 30.html.[12 Maret 2015].

Fatma, Ekasari. 2008. Keperawatan Komunitas. Jakarta : Trans Info Media.

Hidayat, Alimul Aziz. 2013. Metode Penelitian Kebidanan Teknik Analisa Data. Jakarta : Salemba Medika.

Indriasih Endang. 2007. Identifikasi Wilayah Dengan Permasalahan Kesehatan Anak Balita di Provinsi Jatim.

Ismawati, Cahyo, S, dkk. 2010. Posyandu Desa Siaga. Yogyakarta: Nuha Medika.

Kamus Besar Bahasa Indonesia, 2015. Ibu.[Online] (Update 2015). Diakses dari : http://kbbi.web.id/ibu. [13 Maret 2015].

Kemenkes RI. 2014. Profil Kesehatan Indonesia Tahun 2013.

Marimbi, Hanum. 2010. Tumbuh Kembang, Status Gizi dan Imunisasi Dasar pada Balita. Yogyakarta : Nuha Medika.

Mulyani, Nina Siti. 2013. Imunisasi Untuk Anak. Yogyakarta : Nuha Medika.
Nursalam. 2013. Metode Penelitian Keperawatan Pendekatan Praktis Edisi 3. Jakarta : Salemba Medika.

Pengertian Bayi, 2014. Ibu Bayi Balita. [Online] (Update 2014). Diakses dari : http://ibubayibalita.com/pengertianbayi/.[13 Maret 2015].

Prof. Notoatmodjo. Soekidjo. 2005. Promosi Kesehatan dan Aplikasi. Jakarta : PT. Rineka Cipta.

2007. Promosi Kesehatan dan Ilmu Perilaku. Jakarta : PT. Rineka Cipta.

Proverawati, Atikah. 2010. Imunisasi dan Vaksin. Yogyakarta : Nuha Medika.

Purwandari, Atik, Amd.Keb, SKM. 2010. Ilmu Kesehatan Masyarakat dalam Konteks Kebidanan. Jakarta : EGC.

Rikanatalia. 2014. Panduan Lengkap Posyandu untuk Bidan dan Kader. Yogyakarta : Medika Book.

Riyanto, Agus. 2014. Pengetahuan dan Sikap dalam Penelitian Kesehatan. Jakarta : Salemba Medika.

Runjati, M.Mid. 2010. Asuhan Kebidanan Komunitas. Jakarta : EGC.

Soedjatmiko, 2013. Imunisasi. [Online] (Update, 28 Agustus 2013). Diakses dari : http://idai.or.id/publicarticles/klinik/imunisasi/imunisasipenting-untuk-mencegah-penyakitberbahaya.html. [25 Maret 2015].

Sugiyono. 2012. Metode Penelitian Administrasi. Bandung : Alfabeta.

Suharsimi, Arikunto. 2006. Prosedur Penelitian Suatu Pendekatan Praktik. Jakarta : PT. Rineka Cipta. 
Sujarweni, Wiratna. 2014. Metode Penelitian. Yogyakarta : Pustaka Baru.

Tranmiangsih Leni. 2012. Faktor Penyebab Ketdakhadiran Ibu Ke Posyandu.

Unicef. 2009. Lembar Fakta - Imunisasi. Jakarta : Unite For Children.

Wahid Iqbal, Mubarok. 2009. Ilmu Kesehatan Masyarakat Teori dan Aplikasi. Jakarta : Salemba Medika.

Wahid Iqbal, Mubarok. 2011. Promosi Kesehatan Untuk Kebidanan. Jakarta : Salemba Medika.

Wikipedia, 2014. Ibu. [Online] (Update 2014). Diakses dari http://id.m.wikipedia.org/wiki/Ibu. [12Maret 2015].

Wordpress, 2010. Konsep Minat. [Online] (Update, 18 Maret 2010). Diakses dari : https://creasoft.wordpress.com $/ 2010 / 03 / 18 /$ kons ep-minat/.[12 Maret 2015] 
8| Jurnal Kebidanan Dharma Husada Kediri Vol 5. No. 1, April 2016 